\title{
Implementasi Metode Fuzzy AHP pada Sistem Penunjang Keputusan Penentuan Topik Skripsi (Studi Kasus : Program Studi Sistem Informasi Universitas Jember)
}

\author{
(Implementation of Fuzzy AHP Method in Decission Support System Determination of Topic Thesis) \\ ( Case Study :Study Program Information System Jember University)
}

\author{
*Nafta Ryandika Isyaca Fahmi, Antonius Cahya Prihandoko, Windi Eka Yulia Retnani \\ Sistem Informasi, Program Studi Sistem Informasi, Universitas Jember (UNEJ) \\ Jln. Kalimantan 37, Jember 68121 \\ *E-mail: naftaryandikaisyacafahmi@gmail.com
}

\begin{abstract}
Abstrak
Skripsi merupakan istilah yang digunakan di Indonesia untuk mengilustrasikan karya tulis ilmiah berupa paparan tulisan hasil penelitian sarjana strata 1 yang membahas suatu permasalahan dalam bidang tertentu sesuai bidang studi sebagai tugas akhir dalam studi formalnya di perguruan tinggi. Dalam proses penyusunan skripsi terdapat beberapa tahap yang dilalui, tahapan pertama adalah mahasiswa harus menentukan topik dari skripsi yang akan diambil. Terdapat beberapa faktor internal maupun eksternal yang sering menjadi kendala dalam proses pengerjaan skripsi bagi mahasiswa apabila topik yang diambil kurang sesuai dengan kemampuan mahasiswa. Penentuan topik skripsi yang sesuai dengan kemampuan mahasiswa merupakan sebuah persoalan pengambilan keputusan dengan multi kriteria. Penentuan topik skripsi menggunakan kriteria penilaian dari masing-masing kriteria, subkriteria, dan sub-subkriteria. Oleh karena itu diperlukan sebuah sistem penunjang keputusan penentuan topik skripsi yang dapat membantu mahasiswa dalam hal penentuan topik skripsi yang akan diambil berdasarkan kriteria yang telah ditentukan. Metode yang digunakan dalam sistem ini adalah metode Fuzzy Analytical Hierarchy Process (Fuzzy AHP). Metode Fuzzy AHP dipilih karena merupakan sebuah metode yang dapat menangani keputusan multikriteria dengan memperhatikan faktor - faktor subjektivitas, serta memperhitungkan validitas data dengan adanya batas toleransi inkonsistensi dari kriteria yang dipilih yang dikombinasikan dengan pendekatan dengan logika fuzzy, logika fuzzy merupakan sebuah logika yang memiliki nilai fuzzyness antara dua nilai yang diharapkan mampu meminimalisir ketidakpastian sehingga menghasilkan sebuah keputusan yang lebih akurat. Sistem ini dibangun menggunakan bahasa pemrograman Page Hypertext Pre-Processor (PHP) dan framework Code Igniter (CI). Berdasarkan hasil pengujian terhadap sistem, sistem penunjang keputusan dapat melakukan memberikan rekomendasi topik skripsi berdasarkan kemampuan masing-masing mahasiswa.
\end{abstract}

Kata Kunci: Skripsi, Topik Skripsi, Fuzzy AHP, dan sistem penunjang keputusan

\begin{abstract}
A thesis is a term used in Indonesia to illustrate a scientific paper in the form of exposure to writing research scholar stratum 1 which addresses an issue in certain fields according to the field of study as the final project in a formal study in college. In the process of preparation of the thesis, there are several stages to go through, the first stage is, the student should determine the topic of the thesis to be taken. There are several internal and external factors that are often an obstacle in the process of thesis for students if the topic is taken less in line with students' ability. Thesis topic determination in accordance with the ability of students is a problem with a multi-criteria decision making. Determination thesis topic using the assessment criteria of each of the criteria, sub-criteria, and sub-sub-criteria. Therefore we need a decision support system determination thesis topic that can assist students in determining the thesis topic to be taken based on predetermined criteria. The method used in this system is the method of the Fuzzy Analytical Hierarchy Process (Fuzzy AHP). Fuzzy AHP chosen because it is a method that can handle multicriteria decision by taking into account factors - subjectivity factor, as well as take into account the validity of the data with the tolerance limit inconsistency of the selected criteria combined with the approach with fuzzy logic, fuzzy logic is a logic that has value fuzziness between two values that are expected to minimize uncertainties, which produces a more accurate decision. This system is built using a programming language Page Hypertext Pre-Processor (PHP) and the Code Igniter framework (CI). Based on the results of testing of the system, decision support systems can provide recommendations thesis topic is based on the ability of each student.
\end{abstract}

Keywords: Thesis, Thesis Topic, Fuzzy AHP, and Decission Support System

\section{PENDAHULUAN}

Skripsi merupakan suatu bentuk karya ilmiah yang dibuat oleh mahasiswa tingkat akhir berdasarkan hasil penelitian lapangan maupun studi literatur, dan telah diuji kebenarannya berdasarkan data-data yang telah dikumpulkan yang kemudian diolah sehingga menjadi data yang valid yang dapat digunakan sebagai bahan acuan.

Permasalahan yang biasanya dihadapi mahasiswa dalam proses penulisan skripsi diantaranya kesulitan mencari literatur, dana yang terbatas, tidak terbiasa menulis dalam 
arti menulis karya ilmiah, kurang terbiasa dengan sistem kerja terjadwal dengan pengaturan waktu sedemikian ketat dan masalah dengan dosen pembimbing skripsi [1]. Banyaknya mahasiswa yang tidak mempunyai kemampuan dalam tulis menulis, adanya kemampuan akademis yang kurang memadai, serta kurang adanya ketertarikan mahasiswa dalam penelitian [2].

Dalam proses penyusunan skripsi terdapat beberapa tahap yang dilalui, tahapan pertama mahasiswa harus menentukan topik dari skripsi yang akan diambil. Terdapat beberapa faktor internal maupun eksternal yang sering menjadi kendala dalam proses pengerjaan skripsi bagi mahasiswa apabila topik yang diambil kurang sesuai dengan kemampuan mahasiswa. Sebagai contoh di Program Studi Sistem Informasi Universitas Jember dalam pemilihan topik skripsi, mahasiswa terkadang kurang memperhitungkan faktor pendukung serta penghambat dalam penentuan topik skripsi yang akan dibuat. Hal ini akan sulit bagi mahasiswa dalam menentukan topik skripsi yang sesuai apabila ada beberapa faktor penghambat yang berkaitan dengan topik skripsi yang akan diambil tetapi tidak diperhitungkan dengan matang oleh mahasiswa. Oleh karena itu diperlukan sebuah sistem penunjang keputusan penentuan topik skripsi yang dapat membantu mahasiswa yang sedang menempuh skripsi dalam hal penentuan topik skripsi yang akan diambil berdasarkan kriteria yang telah ditentukan.

Metode yang akan digunakan adalah kombinasi antara metode Fuzzy Analytical Hierarchy Process (Fuzzy AHP). Berdasarkan penelitian yang dilakukan oleh Sudri et al. (2014) mengenai perbandingan metode eksis, Analytical Hierarchy Process (AHP), dan Fuzzy AHP dalam pemilihan vendor. Hasil dari penelitian tersebut dijelaskan bahwa metode fuzzy AHP dapat digunakan lebih lanjut dalam proses penilaian vendor karena memiliki kelebihan memiliki bobot kriteria yang dapat disesuaikan dengan tujuan, dapat mendeskripsikan keputusan yang samarsamar, memperhitungkan ketiakpastian, dan dapat meminimalisasi ketidakpastian dalam skala AHP yang berbentuk crisp [3].

Berdasarkan ulasan pada penelitian tersebut metode Fuzzy AHP dipilih karena merupakan sebuah metode yang dapat menangani keputusan multikriteria dengan memperhatikan faktor - faktor subjektivitas, serta memperhitungkan validitas data dengan adanya batas toleransi inkonsistensi dari kriteria yang dipilih. Metode AHP mempunyai kekurangan karena dianggap tidak seimbang dalam skala penilaian perbandingan berpasangan [4]. Skala AHP yang berbentuk bilangan "crisp" (tegas) dianggap kurang mampu menangani ketidakpastian. Oleh karena itu dilakukan pendekatan dengan logika fuzzy, logika fuzzy merupakan sebuah logika yang memiliki nilai fuzzyness antara dua nilai yang diharapkan mampu meminimalisir ketidakpastian sehingga menghasilkan sebuah keputusan yang lebih akurat.

Kombinasi Fuzzy AHP ini diharapkan dapat memberikan gambaran sehingga penentuan topik skripsi yang dipilih oleh mahasiswa di Program Studi Sistem Informasi Universitas Jember lebih tepat dan sesuai dengan kemampuan tiap individu.

\section{METODE PENELITIAN}

Metode penelitian menguraikan tentang metode yang digunakan dalam proses penelitian yang meliputi pengumpulan data, analisis data, pengembangan sistem, dan metode fuzzy AHP.

\section{Pengumpulan data}

Pengumpulan data dilakukan untuk mengumpulkan data dan informasi terkait yang dibutuhkan dalam proses pembangunan sistem. Tahap pengumpulan data yang dilakukan pada penelitian meliputi studi literatur dan wawancara.

\subsection{Studi Literatur}

Studi literatur dilakukan guna menunjang pemahaman dan pengetahuan peneliti mengenai objek penelitian serta metode yang digunakan, pada tahap ini data dan informasi yang dibutuhkan diperoleh dari lokasi penelitian yaitu Universitas Jember. Selain itu studi literatur juga diperoleh dari paper, jurnal ilmiah, buku referensi terkait.

1.2 Wawancara

Wawancara merupakan salah satu cara yang dilakukan untuk mendapatkan data dan informasi langsung dari narasumber. Peneliti melakukan wawancara pada dosen yang menjadi anggota komisi bimbingan (KOMBI), dan mahasiswa. Wawancara yang dilakukan dengan komisi bimbingan dilakukan guna mendapatkan bussiness requirement dari sistem, dan membahas mengenai pembobotan dari masing-masing kriteria dan subkriteria yang akan digunakan, sedangkan wawancara yang dilakukan kepada mahasiswa dilakukan guna mendapatkan user requirement dari sistem yang akan dibangun.

\section{Analisis data}

Tahap analisis data dilakukan setelah proses pengumpulan data mengenai topik skripsi telah selesai dilakukan. Data yang telah diperoleh kemudian dianalisis dengan menggunakan metode fuzzy AHP yang akan digunakan untuk membangun sistem pendukung keputusan penentuan topik skripsi dengan metode fuzzy AHP. Sistem menerima input kriteria kriteria (mata kuliah, minat, kendala, rekomendasi dosen, ketersediaan referensi dan penjurusan) dan alternatif (topik skripsi) yang akan diproses menggunakan metode fuzzy AHP, dan menghasilkan perangkingan alternatif berupa bobot penilaian topik skripsi dengan hasil keputusan berupa daftar ranking.

\section{Pengembangan sistem}

Dalam tahap pembangunan sistem penunjang penentuan topik skripsi dengan metode fuzzy AHP dikembangkan menggunakan Software Development Life cycle (SDLC) dengan mengadopsi metode waterfall.

Waterfall [5] merupakan model sekuensial, sehingga dalam proses penyelesaian satu set kegiatan menyebabkan dimulainya aktivitas berikutnya secara sistematis dari satu tahap pengembangan dari satu tahap ke tahap lainnya. Tahapan SDLC dengan model Waterfall dapat dilihat pada gambar 1. Dimana pada gambar 1 dapat dijelaskan bahwa terdapat 5 tahap pada SDLC dengan metode waterfall yaitu analisis data, perancangan sistem, implementasi, pengujian sistem, dan pemeliharaan sistem. 


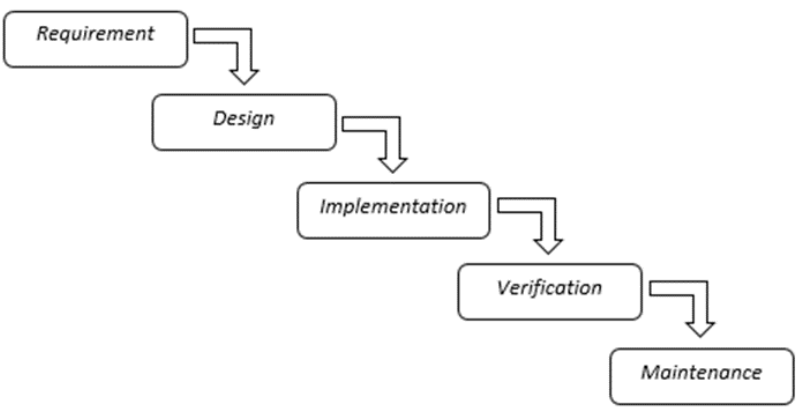

Gambar 1. Waterfall Model [5]

\section{Metode fuzzy AHP}

Fuzzy AHP (F-AHP) merupakan penggabungan metode antara AHP dengan pendekatan konsep fuzzy. Metode Fuzzy-AHP dapat menutupi kekurangan metode AHP, yaitu ketidakpresisian dalam mengatasi Multi criteria decision making yang memiliki kriteria yang bersifat subjektif. [6] mengembangkan metode Fuzzy-AHP dengan menggunakan fungsi keanggotaan segitiga atau Triangular Fuzzy Number untuk menggantikan skala 1-9 pada pairwase comparation pada metode AHP dalam menentukan derajat keanggotaan.

Langkah-langkah metode fuzzy AHP yaitu menentukan kriteria yang akan digunakan serta memberikan nilai perbandingan antar kriteria sehingga menghasilkan matriks keputusan, selanjutnya dilakukan fuzzifikasi matriks keputusan sehingga diperoleh matriks fuzzy, kemudian dilakukan proses perhitungan prioritas fuzzy dengan menggunakan metode extent analysis selanjutnya melakukan defuzzifikasi untuk mendapatkan nilai crisp yang kemudian dilakukan normalisasi untuk mendapatkan nilai bobot kriteria. Diagram alir penentuan topik skripsi dengan menggunakan metode fuzzy AHP dapat dilihat pada gambar 2 .

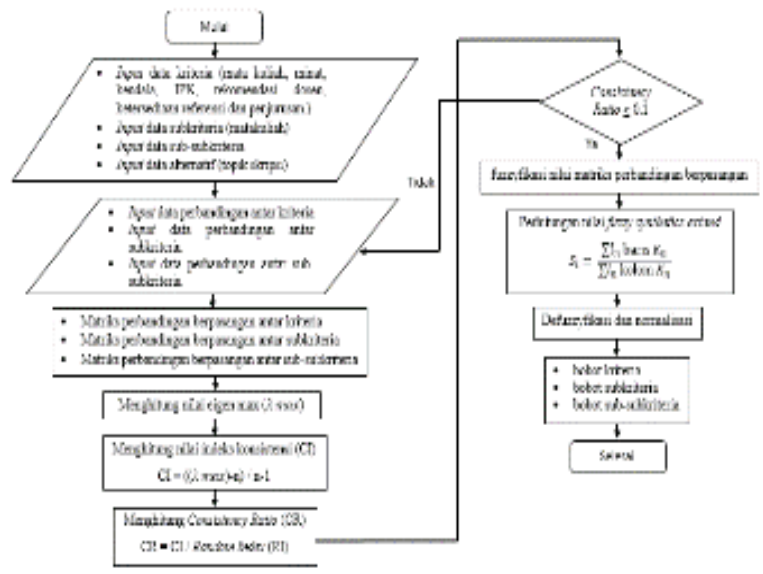

Gambar 2. Diagram alir penentuan topik skripsi dengan fuzzy AHP

\section{Desain dan Perancangan Sistem}

Desain pada sistem pendukung keputusan penentuan topik skripsi dapat digambarkan melalui analisis kebutuhan, bussiness process, use case diagram, dan entity relationship diagram. Pada analisis kebutuhan terdapat kebutuhan fungsional. Kebutuhan fungsional sistem pada penelitian ini adalah sebagai berikut: a. Sistem dapat memperbaharui data komisi bimbingan

b. Sistem dapat menampilkan data komisi bimbingan

c. Sistem dapat menampilkan data kriteria

d. Sistem dapat memperbaharui data perbandingan antar kriteria

e. Sistem dapat menampilkan data perbandingan antar kriteria

f. Sistem dapat menampilkan data subkriteria

g. Sistem dapat memperbaharui data perbandingan antar subkriteria

h. Sistem dapat menampilkan data perbandingan antar subkriteria

i. Sistem dapat menampilkan data sub-subkriteria

j. Sistem dapat memperbaharui data perbandingan antar sub-subkriteria

k. Sistem dapat menampilkan data perbandingan antar subsubkriteria

1. Sistem dapat memberikan rekomendasi mahasiswa dalam penentuan topik skripsi

$\mathrm{m}$. Sistem dapat memperbaharui data user

n. Sistem dapat menampilkan data user

o. Sistem dapat melakukan regristrasi user

Sedangkan kebutuhan non-fungsional sistem pada penelitian ini adalah sistem berbasis web dan sistem menggunakan framework codeigniter.

Business process merupakan gambaran input dan output dari sebuah sistem serta tujuan dari sistem tersebut dibuat. Business process sistem penunjang keputusan penentuan topik skripsi dapat ditunjukkan pada gambar 3 .

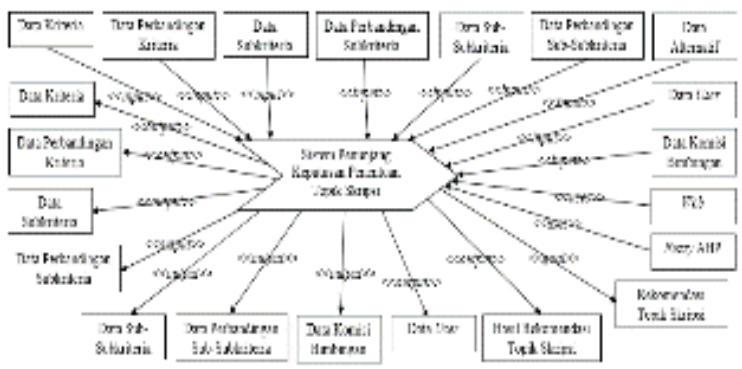

Gambar 3. Business Process

Berdasarkan pada gambar 3, input dari sistem adalah data kriteria, data perbandingan kriteria, data subkriteria, data perbandingan subkriteria, data sub-subkriteria, data perbandingan sub-subkriteria, data alternatif, data komisi bimbingan, dan data user selanjutnya output dari sistem adalah data kriteria, data perbandingan kriteria, data subkriteria, data perbandingan subkriteria, data subsubkriteria, data perbandingan sub-subkriteria, data komisi bimbingan, dan data user. Goal dari sistem ini adalah hasil rkomendasi topik skripsi dengan uses web dan metode fuzzy AHP.

Use case adalah rangkaian / uraian sekelompok yang saling terkait dan membentuk sistem secara teratur yang dilakukan atau diawasi oleh sebuah aktor. Use case sistem dapat dilihat pada gambar 4 . 


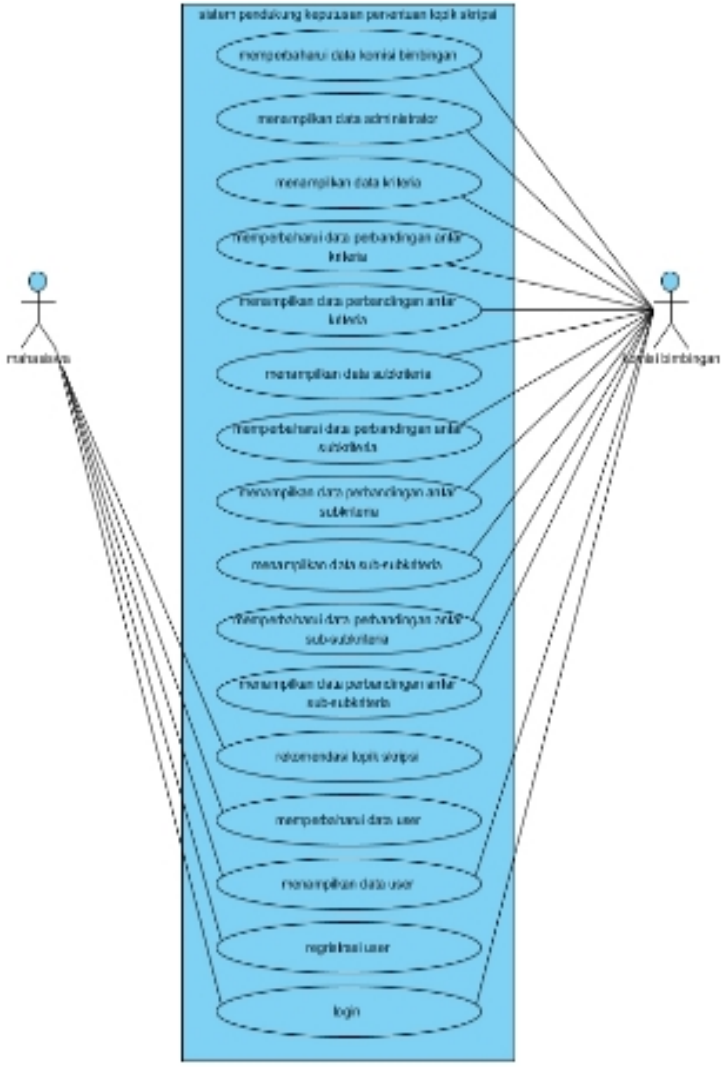

Gambar 4. UseCase

Dalam use case tersebut terdapat 2 aktor yaitu mahasiswa dan komisi bimbingan. User mahasiswa mempunyai hak akses untuk mengakses fitur rekomendasi topik skripsi, memperbaharui topik skripsi, memperbaharui data user, dan regristrasi user sedangkan fitur yang terdapat pada hak akses user komisi bimbingan adalah melihat data kriteria, memperbaharui bobot data perbandingan kriteria, melihat data perbandingan antar kriteria, melihat data subkriteria, memperbaharui data bobot perbandingan antar subkriteria, melihat data perbandingan antar subkriteria, melihat data sub-subkriteria, memperbaharui data bobot perbandingan antar sub-subkriteria, melihat data perbandingan antar sub-subkriteria, memperbaharui data administrator, dan melihat data user serta login.

Entity relationship diagram merupakan suatu model untuk menjelaskan hubungan antar data dalam basis data berdasarkan objek-objek dasar data yang mempunyai hubungan antar relasi. Entity relationship diagram digunakan untuk memodelkan struktur data dan hubungan antar data, untuk menggambarkannya digunakan beberapa notasi dan simbol. Entity relationship diagram sistem pendukung keputusan penentuan topik skripsi dapat dilihat pada gambar 5 .

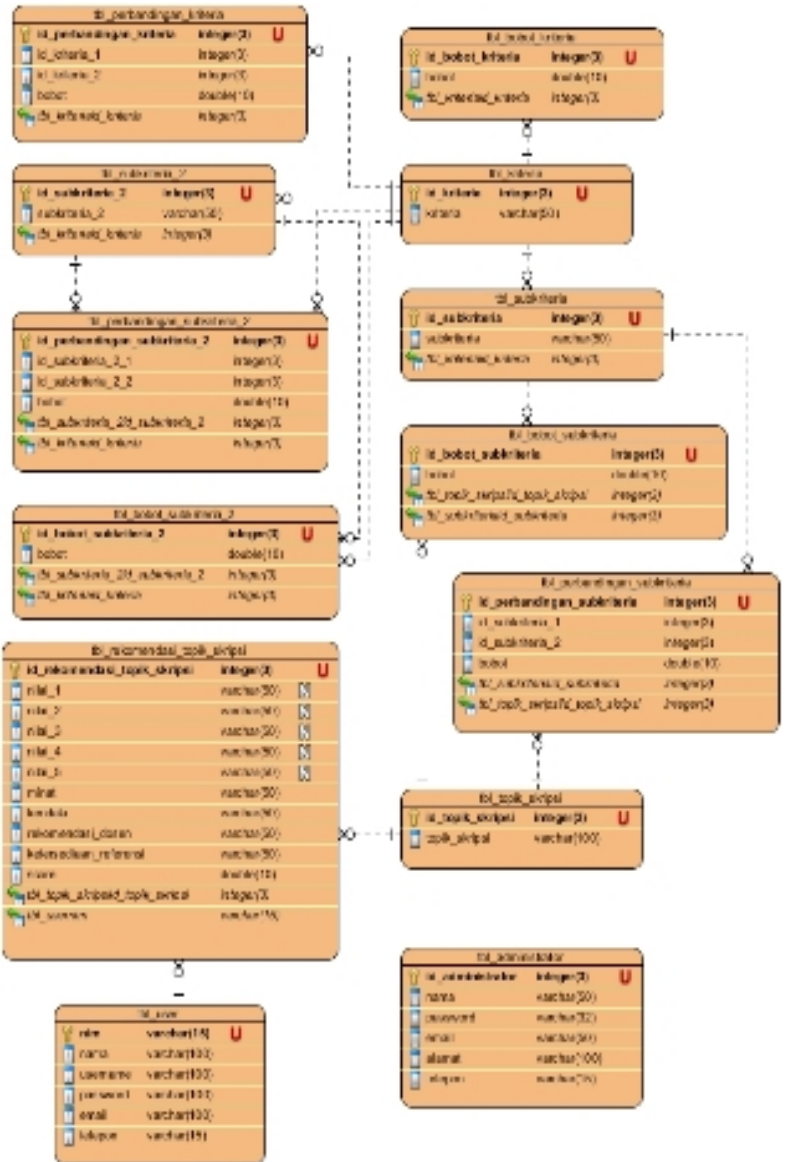

Gambar 5. Entity Relationship Diagram

Berdasarkan gambar 5 dapat dijelaskan bahwa sistem penunjang keputusan penentuan topik skripsi mempunyai 13 tabel yang akan digunakan pada sistem antara lain digunakan untuk menyimpan data yang berhubungan hasil perbandingan antar kriteria, subkriteria, dan sub-subkriteria serta data user dan komisi bimbingan. tbl kriteria , tbl_perbandingan_kriteria, dan tbl bobot kriteria merupakan tabel yang berkaitan dengan penyimpanan data kriteria, tbl_subkriteria , tbl_perbandingan_subkriteria ,dan tbl_bobot_subkriteria merupakan tabel yang berkaitan dengan penyimpanan data subkriteria, tbl subkriteria 2 , tbl_perbandingan_subkriteria_2 ,dan tbl_bobot_subkriteria_2 merupakan tabel yang berkaitan dengan penyimpanan data sub-subkriteria selanjutnya tbl_rekomendasi_topik_skripsi yang berkaitan dengan penyimpanan hasil rekomendasi topik skripsi, tbl_topik_skripsi yang berisi tentang topik skripsi yang dapat direkomendasikan serta tbl_user dan tbl_administrator yang berisi data pengguna sistem. 


\section{PEMBAHASAN}

Hasil implementasi sistem pendukung keputusan penentuan topik skrpsi dengan menggunakan metode fuzzy AHP pada penelitian ini terdapat dua hak (komisi bimbingan dan mahasiswa). Komisi bimbingan mempunyai hak akses beberapa fitur utama yaitu melihat data kriteria, memperbaharui bobot data perbandingan kriteria, melihat data perbandingan antar kriteria, melihat data subkriteria, memperbaharui data bobot perbandingan antar subkriteria, melihat data perbandingan antar subkriteria, melihat data sub-subkriteria, memperbaharui data bobot perbandingan antar sub-subkriteria, melihat data perbandingan antar subsubkriteria, memperbaharui data administrator, dan melihat data user. Sedangkan pada hak akses mahasiswa terdapat fitur rekomendasi topik skripsi, memperbaharui data user, menampilkan data user, dan regristrasi user.

Implementasi metode fuzzy AHP pada penelitian ini terdapat pada fitur memperbaharui bobot perbandingan kriteria, memperbaharui bobot perbandingan subkriteria, dan memperbaharui bobot perbandingan sub-subkriteria. Fitur memperbaharui bobot perbandingan kriteria dapat dilihat pada gambar 6 .

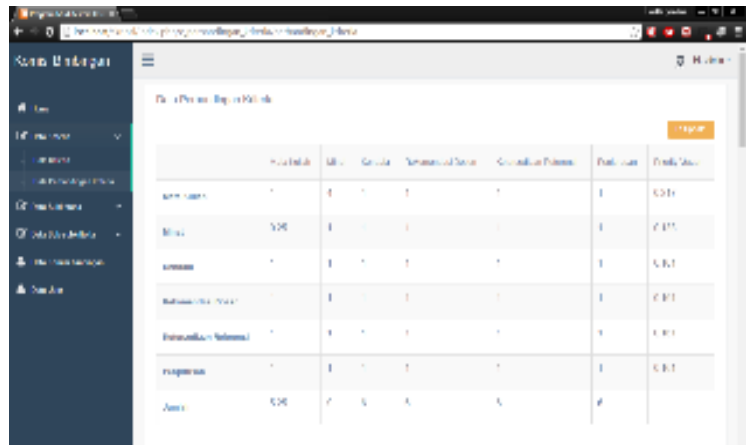

Gambar 6. Halaman Data Perbandingan Kriteria

Data kriteria yang digunakan pada sistem kemudian akan dilakuan proses pembobotan. Nilai pembobotan yang telah diinputkan kemudian akan diproses menngunakan metode fuzzy AHP sehingga didapatkan nilai lamda max, CI, CR, prioritas AHP serta bobot lokal (Wlokal). Hasil perhitungan matriks perbandingan berpasangan kriteria menggunakan metode fuzzy AHP dapat dilihat pada Gambar 7 dan Gambar 8.

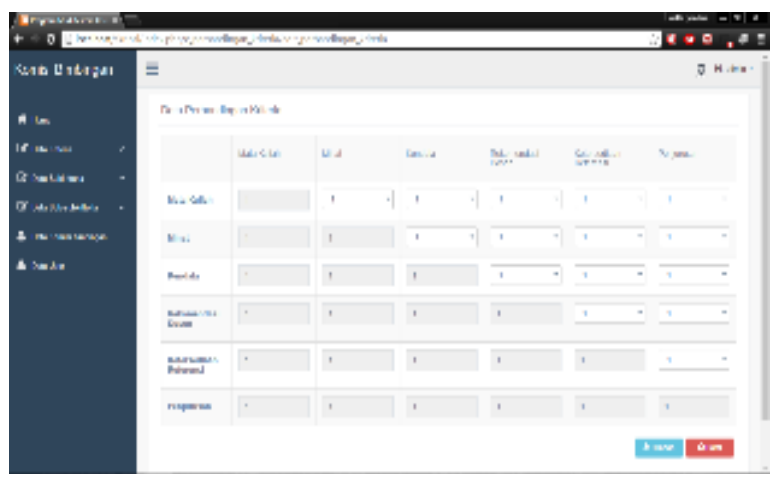

Gambar 7. Halaman Edit Perbandingan Kriteria
Nilai Bobot Kriteria

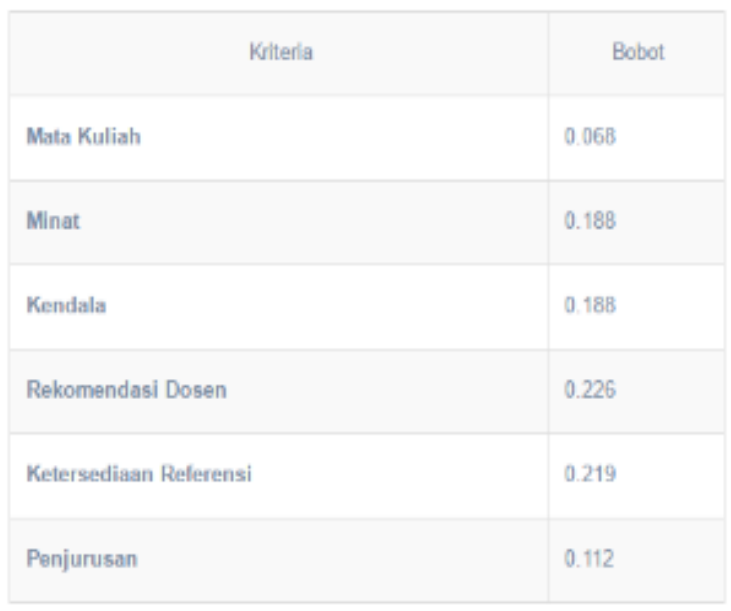

Gambar 8. Hasil Bobot Kriteria

Pengujian rekomendasi topik skripsi bertujuan untuk menilai kinerja dari sistem. Pengujian dilakukan dengan melakukan rekomendasi dengan membuat salah satu topik skripsi bernilai tinggi, sedang, dan rendah, hal ini bertujuan untuk mengetahui tingkat keakuratan sistem. Hasil rekomendasi topik skripsi dapat dilihat pada gambar 9 .

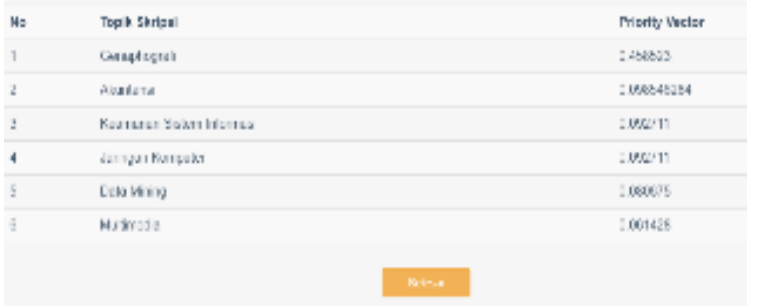

Berdasarkan hasil pengujian yang dilakukan pada fitur rekomendasi topik skripsi, hasil rekomendasi topik skripsi yang diberi nilai tinggi (Genaphografi) akan menghasilkan nilai yang tinggi, hasil rekomendasi topik skripsi yang bernilai sedang (Akuntansi, Keamanan sistem informasi, Jaringan komputer, dan Data mining) juga akan menghasilkan rekomendasi yang bernilai sedang, dan hasil rekomendasi topik skripsi yang diberi nilai rendah (mutimedia) akan menghasilkan rekomendasi yang rendah sehingga hasil rekomendasi topik skripsi dengan menggunakan metode fuzzy AHP akurat.

\section{KESIMPULAN}

1. Sistem pendukung keputusan ini menggunakan metode fuzzy AHP. Metode AHP digunakan untuk membuat matriks perbandingan antar kriteria, matriks perbandingan antar subkriteria, dan matriks perbandingan antar subsubkriteria serta menguji konsistensi dari matriks perbandingan berpasangan. Apabila matriks konsisten atau nilai $\mathrm{CR} \leq 0.1$ maka matriks akan diubah kedalam skala triangular fuzzy number dengan menggunakan metode fuzzy, sehingga akan didapat bobot dari masing-masing kriteria ,subkriteria, dan sub-subkriteria yang akan digunakan dalam proses rekomendasi topik skripsi. 
2. Sistem pendukung keputusan penentuan topik skripsi menggunakan metode fuzzy AHP dibangun untuk membantu mahasiswa semester akhir yang akan atau sedang menempuh skripsi agar lebih mudah dalam penentuan topik yang akan diambil sesuai dengan kemampuan dan minat yang dimiliki sehingga meminimalisir hambatan dalam proses penyusunan skripsi. Sistem ini dibangun dengan 2 hak akses (komisi bimbingan dan mahasiswa) dengan beberapa fitur yaitu melihat data kriteria, memperbaharui bobot data perbandingan kriteria, melihat data perbandingan antar kriteria, melihat data subkriteria, memperbaharui data bobot perbandingan antar subkriteria, melihat data perbandingan antar subkriteria, melihat data sub-subkriteria, memperbaharui data bobot perbandingan antar sub-subkriteria, melihat data perbandingan antar sub-subkriteria, memperbaharui data komisi bimbingan, dan melihat data user pada hak akses komisi bimbingan. Sedangkan pada hak akses mahasiswa terdapat fitur rekomendasi topik skripsi, memperbaharui data user, menampilkan data user, dan regristrasi user. Dalam perancangan dan pembangunan sistem penunjang keputusan penentuan topik skripsi ini memperhatikan kesesuaian antara desain sistem dengan implementasinya.

3. Berdasarkan hasil penelitian yang telah dilakukan sistem. Penunjang keputusan penentuan topik skripsi ini menggunakan 6 kriteria yang digunakan dalam proses rekomendasi topik skripsi yaitu : mata kuliah, minat, kendala, rekomendasi dosen, ketersediaan referensi, dan penjurusan. Kriteria mata kuliah memiliki subkriteria genaphografi, akuntansi, keamanan sistem informasi, jaringan komputer, data mining, dan multimedia.

4. Metode fuzzy AHP menghasilkan bobot pada masingmasing kriteria (mata kuliah $=0.068$, minat $=0.188$, kendala $=0.188$, rekomendasi dosen $=0.226$, ketersediaan referensi $=0.219$, dan penjurusan $=0.112$ ).

5. Penentuan bobot untuk matriks perbandingan berpasangan antar kriteria, matriks berpasangan antar subkrteria maupun matriks perbandingan antar subsubkriteria berpengaruh pada hasil rekomendasi topik skripsi yang diberikan sistem sehingga membutuhkan pengamatan lebih dalam dalam pemberian bobot.

6. Metode fuzzy AHP dapat digunakan untuk proses memberikan rekomendasi topik skripsi dan sistem yang dibangun dapat melakukan proses rekomendasi topik skripsi seperti yang diinginkan. Pada sistem pendukung keputusan ini didapatkan hasil rekomendasi topik skripsi dengan menerapkan metode fuzzy AHP dimana semakin tinggi nilai topik skripsi maka topik skripsi tersebut semakin direkomendasikan untuk mahasiswa begitu juga sebaliknya.

\section{SARAN}

1. Sistem penunjang keputusan penentuan topik skripsi dapat digunakan secara dinamis dengan mampu menambah kriteria, subkriteria, dan sub-subkriteria yang ada.

2. Sistem penunjang keputusan penentuan topik skripsi dapat terintegrasi dengan daftar semua mahasiswa agar mampu menyimpan data pribadi semua mahasiswa pada sistem.
3. Pengembangan lebih lanjut untuk penelitian ini dapat dilakukan dengan membangun sistem penunjang keputusan dengan menggunakan metode perangkingan yang lain agar dapat diciptakan perbandingan antara dua metode.

\section{DAFTAR PUSTAKA}

[1] Darmono, dan Hasan A.M. 2008. Menyelesaikan skripsi dalam satu semester. Jakarta : Gramedia Widiasarana Indonesia . hal 5-6.

[2] Master,J. 2013. Kendala Mahasiswa dalam Menulis Skripsi

http://staff.unila.ac.id/janter/2012/05/30/kendalamahasiswa-dalam-menulis-skripsi/ [14 Maret 2015]

[3] Sudri, N. M., Nendisa, B. C., dan Wibisono, S. 2014. "Perancangan Vendor Appraisal dengan Metode Fuzzy Analytical Hierarchy Process pada PT XYZ “. Jurnal Teknik dan Ilmu Komputer Vol. 03 No. 10, hal 138-144.

[4] Anshori, Y. 2012. "Pendekatan Triangular Fuzzy Number dalam Metode Analytic Hierarchy Process". Jurnal Ilmiah Foristek Vol. 2, No. 1, Maret 2012 hal. $126-135$.

[5] Fahrurrozi, I., dan Azhari, S.N. (Tanpa Tahun). "Proses Pemodelan Software Dengan Metode Waterfall Dan Extreme Programming: Studi Perbandingan”. Tidak Dipublikasikan. Program Studi Ilmu Komputer Universitas Gadjah Mada.

[6] Chang, D. (1996). "Applications of The Extent Analysis Method on Fuzzy AHP. European Jurnal of Operational Research", 649-655. 